\title{
Patient, Clinician, and Communication Factors Associated with Colorectal Cancer Screening
}

\author{
Alex H. Krist, MD, MPH, Camille J. Hochbeimer, PhD, Roy T. Sabo, PhD, \\ Jon Puro, MHA, Eric Peele, Paulette Lail-Kashiri, MPH, and Sally W. Vernon, PhD
}

Introduction: Screening for colorectal cancer is beneficial. Yet, screening remains suboptimal, and underserved populations are at greater risk for not being appropriately screened. Although many barriers to screening are understood, less is known about how the decision-making process on whether to receive colonoscopy or stool testing influences screening.

Methods: As part of a randomized controlled trial to test engaging underserved populations in preventive care through online, personalized, educational material, 2417 patients aged 50 to 74 years were randomly selected from the $\mathbf{7 0 , 9 9 8}$ patients with an office visit the year prior and mailed a survey to assess decision-making for colorectal cancer screening. Twenty practices in practice-based research networks from 5 diverse states participated. Survey data were supplemented with electronic health record data.

Results: Among respondents, $64 \%$ were or became up to date with screening within 3 months of their office visit. The main factor associated with being up to date was the length of the patient-clinician relationship ( $<6$ months vs $5+$ years: odds ratio [OR], 0.49; 95\% CI, 0.30-0.80). Sharing the decision about screening options with the clinician was a predictor for being up to date compared with patients who made the decision for themselves (OR, 1.75; 95\% CI, 1.27-2.44). Only 36\% of patients reported being given a choice about screening options. Traditional factors like race, employment, insurance, and education were not associated with screening.

Conclusions: Having a long-term relationship with a primary care clinician and sharing decisions may be key drivers to ensure evidence-based preventive care for underserved populations. (J Am Board Fam Med 2020;33:779-784.)

Keywords: Colorectal Cancer, Decision-Making, Early Detection of Cancer, Mass Screening, Physician-Patient Relations, Practice-Based Research, Primary Health Care, Surveys and Questionnaires, Vulnerable Populations

\section{Introduction}

Colorectal cancer screening saves lives; yet, less than two-thirds of Americans who should be screened are up to date with screening. ${ }^{1}$ Minorities, individuals

This article was externally peer reviewed.

Submitted 15 October 2019; revised 1 May 2020; accepted 9 May 2020.

From the Department of Family Medicine and Population Health, Virginia Commonwealth University, Richmond (AHK, CJH, RTS, PL-K), Department of Biostatistics, Virginia Commonwealth University, Richmond (CJH, RTS); OCHIN, Portland, OR (JP), RTI International, Research Triangle Park, NC (EP), Department of Health Promotion and Behavioral Sciences, School of Public Health, University of Texas Health Science Center at Houston, Houston (SWV).

Funding: Funding for this study is provided by the National Cancer Institute (R01CA166375-01A1), the National Center for Advancing Translational Sciences (UL1TR002649), and VCU Massey Cancer Center Biostatistical Shared Resource, supported, in part, with living in poverty, uninsured, and Medicaid beneficiaries disproportionately suffer greater morbidity and mortality from colorectal cancer. ${ }^{2}$ Although there is some debate as to whether biologic factors contribute to disparities in colorectal cancer outcomes for minorities, there is clear evidence that a lack of screening, delays in starting screening, inadequate follow-up of abnormal results, and treatment delays

funding from NIH-NCI Cancer Center Support Grant P30 CA016059. The opinions expressed in this manuscript are those of the authors and do not necessarily reflect those of the funders.

Disclaimer: This article does not necessarily represent the views and policies of the USPSTF.

Conflict of interest: Dr. Krist is a member of the United States Preventive Services Task Force (USPSTF).

Corresponding author: Alex H. Krist, One Capital Square Room 631, 830 East Main St, Richmond, VA 23219 (E-mail: alexander.krist@vcuhealth.org). 
are all factors. ${ }^{3,4}$ Accordingly, a major focus of care has been to ensure that all adults age 50 to 74 years complete colon cancer screening.

Top barriers to screening include not knowing that screening is indicated, not being told by a clinician to be screened, financial concerns, misconceptions on benefits and harms of screening, fear about finding cancer, and test-specific barriers (eg, not wanting to handle stool or not wanting to do a bowel preparation). ${ }^{5}$ Interventions such as one-onone education, clinician and patient alerts and reminders, reduced out-of-pocket expenses, and reduced structural barriers have all been shown to increase screening rates. ${ }^{6}$

Although the barriers to screening are well documented and there are interventions to promote screening, less is known about the relative importance of patient, clinician, health system, and communication factors associated with recommended screening, particularly for more underserved populations. Knowing the relative importance of these barriers may help to inform which interventions should be prioritized for implementation.

\section{Methods}

As part of a randomized controlled trial to evaluate engaging underserved patients in preventive care, we analyzed electronic health records (EHRs) and patient survey responses about clinical encounters. The full study protocol has been previously published, and the study and survey were approved by the Virginia Commonwealth University Institutional Review Board (HM15307). ${ }^{7}$

This study was conducted in 2 practice-based research networks (PBRNs): the Virginia Ambulatory Care Outcomes Research Network and the OCHIN community health information network. Twenty safety net practices and community health centers in 5 states with a wide geographic distribution participated. Among 70,998 patients seen for an office visit between November and July 2016, 4336 patients aged 40 to 75 were randomly mailed a survey, of which 2417 included questions about the colorectal cancer screening decision-making process.

Survey questions asked patients about their demographics, desired and actual locus of decision-making control, ${ }^{8}$ satisfaction with clinician communication, ${ }^{9}$ decisional conflict, ${ }^{10}$ length of patient-clinician relationship (ie, "How long have you been going to your doctor?"), and the single-item quality of life question.
Locus of decision-making included 5 options: "I prefer to make the decision," "I prefer to make the decision after considering my clinician's opinion," "I prefer to share the decision with my clinician," "I prefer for my clinician to make the decision after considering my opinion," and "I prefer my clinician to make the decision." ${ }^{8}$ Satisfaction with clinician communication was assessed using the 4 clinician communication questions from the Consumer Assessment of Health care Providers and Systems Clinician \& Group Survey. ${ }^{9}$ Response options included never, sometimes, usually, and always, which are scored as $1,2,3$, and 4, respectively. Decisional conflict was assessed using the 10-question simplified Decisional Conflict Scale. Questions were grouped into 4 subscales and scored per standard protocol, with an overall score under 25 being correlated with a greater likelihood of patients being able to make a decision, and a score over 37 being correlated with a greater likelihood that a patient will not be able to make a decision. ${ }^{10}$

EHR data included diagnoses, colorectal cancer screening tests and dates, race/ethnicity, and insurance type. Being up to date with screening was based on the 2016 US Preventive Services Task Force recommendation 3 months after the index office visit (eg, colonoscopy within 10 years and stool test within 1 year). ${ }^{1}$ Information about clinician characteristics (age, gender, race/ethnicity, specialty training, and concordance with patient) were collected from PBRN member records.

Associations between clinician, patient, and decision-making characteristics and being up to date with colorectal cancer screening were compared. Categorical variables were summarized with frequencies, and continuous variables were summarized with means and standard deviations. $\chi^{2}$ tests compared frequencies, except in cases of small sample sizes, for which Fisher's exact test was used. $t$ test compared differences in means between patients who were and were not up to date. Analyses were completed using the SAS version 9.4 software (Cary, NC) in January 2019.

\section{Results}

Of 2417 patients mailed surveys with colorectal cancer screening questions, 1068 completed the survey (44\%), and we were able to match EHR data for 959 patients eligible for screening. A total of 587 of 959 patients $(61 \%)$ were up to date with 
Table 1. Association between Patient Characteristics and Colorectal Cancer Screening Up-to-Datedness."

\begin{tabular}{|c|c|c|c|}
\hline Characteristic & $\begin{array}{l}\text { Number of Patients Up to Date } \\
\qquad(\mathrm{n}=618)^{\dagger}\end{array}$ & $\begin{array}{l}\text { Number of Patients Not Up to Date } \\
\qquad(\mathrm{n}=341)^{\dagger}\end{array}$ & $P$ Value \\
\hline Female & $391(63.3 \%)$ & $201(58.9 \%)$ & .19 \\
\hline Age & $61.7(5.7)$ & $60.8(5.8)$ & .02 \\
\hline Race & & & ${ }^{\ddagger} .15$ \\
\hline Asian & $7(1.1 \%)$ & $5(1.5 \%)$ & \\
\hline Black & $205(33.4 \%)$ & $89(26.6 \%)$ & \\
\hline White & $397(64.8 \%)$ & $239(71.3 \%)$ & \\
\hline Other & $4(0.7 \%)$ & $2(0.6 \%)$ & \\
\hline Hispanic & $12(2.0 \%)$ & $10(3.0 \%)$ & .32 \\
\hline Insurance & & & .22 \\
\hline Commercial & $229(37.1 \%)$ & $127(37.2 \%)$ & \\
\hline Medicaid & $73(11.8 \%)$ & $52(15.3 \%)$ & \\
\hline Medicare & $257(41.6 \%)$ & $123(36.1 \%)$ & \\
\hline Uninsured & $59(9.5 \%)$ & $39(11.4 \%)$ & \\
\hline Occupational status & & & .50 \\
\hline Employed & $241(39.6 \%)$ & $140(41.4 \%)$ & \\
\hline Unemployed & $33(5.4 \%)$ & $18(5.3 \%)$ & \\
\hline Homemaker & $12(2.0 \%)$ & $7(2.1 \%)$ & \\
\hline Student & $1(0.2 \%)$ & $1(0.3 \%)$ & \\
\hline Retired & $214(35.1 \%)$ & $99(29.3 \%)$ & \\
\hline Disabled & $108(17.7 \%)$ & $73(21.6 \%)$ & \\
\hline Marital status & & & .62 \\
\hline Married & $316(51.9 \%)$ & $164(48.8 \%)$ & \\
\hline Living as married & $20(3.3 \%)$ & $10(3.0 \%)$ & \\
\hline Divorced & $134(22.0 \%)$ & $77(22.9 \%)$ & \\
\hline Widowed & $46(7.5 \%)$ & $31(9.2 \%)$ & \\
\hline Separated & $19(3.1 \%)$ & $6(1.8 \%)$ & \\
\hline Single, never been married & $74(12.2 \%)$ & $48(14.3 \%)$ & \\
\hline Education & & & .86 \\
\hline Less than $8^{\text {th }}$ grade & $22(3.6 \%)$ & $13(3.9 \%)$ & \\
\hline Completed some high school & $43(7.1 \%)$ & $23(6.9 \%)$ & \\
\hline High school graduate/GED ${ }^{\S}$ & $143(23.5 \%)$ & $87(26.2 \%)$ & \\
\hline Some college & $166(27.3 \%)$ & $92(27.7 \%)$ & \\
\hline College degree or higher & $234(38.5 \%)$ & $117(35.2 \%)$ & \\
\hline Quality of life & & & .71 \\
\hline Excellent & $41(6.7 \%)$ & $18(5.4 \%)$ & \\
\hline Very good & $180(29.3 \%)$ & $99(29.5 \%)$ & \\
\hline Good & $250(40.7 \%)$ & $138(41.1 \%)$ & \\
\hline Fair & $122(19.9 \%)$ & $64(19.0 \%)$ & \\
\hline Poor & $21(3.4 \%)$ & $17(5.0 \%)$ & \\
\hline Duration of patient-clinician relationship & & & .02 \\
\hline Less than 6 months & $41(6.7 \%)$ & $36(10.6 \%)$ & \\
\hline 6 months to a year & $43(7.0 \%)$ & $31(9.1 \%)$ & \\
\hline 1 to 3 years & $132(21.4 \%)$ & $84(24.6 \%)$ & \\
\hline 3 to 5 years & $110(17.9 \%)$ & $66(19.3 \%)$ & \\
\hline 5 or more years & $289(47.0 \%)$ & $124(36.4 \%)$ & \\
\hline
\end{tabular}

*959 patients eligible for cancer screening from 20 community health centers completed the survey.

${ }^{\dagger}$ Percentages report the characteristics of those who are (or are not) up to date for each category.

${ }^{\ddagger}$ Indicates Fisher's exact test used in place of $\chi^{2}$ test.

${ }^{\S}$ GED, General Educational Development.

Bolded $p$ values are statistically significant. 
Table 2. Association between Patient-Reported Decision-Making and Colorectal Cancer Screening Up-to-

Datedness $(\mathrm{n}=959)$

\begin{tabular}{|c|c|c|c|}
\hline Survey Response & $\begin{array}{l}\text { Number of Patients Up to } \\
\text { Date }(\mathrm{n}=618)^{*}\end{array}$ & $\begin{array}{l}\text { Number of Patients Not Up to } \\
\text { Date }(\mathrm{n}=341)^{*}\end{array}$ & $\begin{array}{c}P \\
\text { Value }\end{array}$ \\
\hline Were given a choice about screening options & $192(57.5 \%)$ & $142(42.5 \%)$ & $<.01$ \\
\hline \multicolumn{4}{|l|}{ Locus of decision-making control } \\
\hline How patients want to make decision & & & $<.01$ \\
\hline $\begin{array}{l}\text { I prefer to make the final decision myself or after } \\
\text { seriously considering my doctor's opinion. }\end{array}$ & $283(59.7 \%)$ & $191(40.3 \%)$ & \\
\hline $\begin{array}{l}\text { I prefer that my doctor and I share the responsibility for } \\
\text { making the final decision. }\end{array}$ & $264(70.8 \%)$ & $109(29.2 \%)$ & \\
\hline $\begin{array}{l}\text { I prefer my doctor make the final decision or makes the } \\
\text { final decision after seriously considering my opinion. }\end{array}$ & $61(67.8 \%)$ & $29(32.2 \%)$ & \\
\hline How decision was actually made & & & $<.01$ \\
\hline $\begin{array}{l}\text { I made the final decision myself or after seriously } \\
\text { considering my doctor's opinion. }\end{array}$ & $301(59.5 \%)$ & $205(40.5 \%)$ & \\
\hline $\begin{array}{l}\text { My doctor and I shared the responsibility for making } \\
\text { the final decision }\end{array}$ & $190(72.0 \%)$ & $74(28.0 \%)$ & \\
\hline $\begin{array}{l}\text { My doctor made the final decision or made the final } \\
\text { decision after seriously considering my opinion. }\end{array}$ & $74(74.0 \%)$ & $26(26.0 \%)$ & \\
\hline $\begin{array}{l}\text { Concordance between preferred and actual locus of } \\
\text { decision control }\end{array}$ & $399(65.5 \%)$ & $210(34.5 \%)$ & .75 \\
\hline \multicolumn{4}{|l|}{ Clinician communication $^{\dagger}$} \\
\hline $\begin{array}{l}\text { How often did your doctor explain things in a way that } \\
\text { was easy to understand? }\end{array}$ & $3.8(0.5)$ & $3.7(0.6)$ & .05 \\
\hline How often did your doctor listen carefully to you? & $3.8(0.5)$ & $3.7(0.5)$ & .52 \\
\hline $\begin{array}{l}\text { How often did your doctor show respect for what you had } \\
\text { to say? }\end{array}$ & $3.8(0.5)$ & $3.7(0.6)$ & .20 \\
\hline How often did your doctor spend enough time with you? & $3.7(0.6)$ & $3.6(0.7)$ & .14 \\
\hline Overall average score & $3.8(0.5)$ & $3.7(0.5)$ & .18 \\
\hline \multicolumn{4}{|l|}{ Decisional conflict score ${ }^{\ddagger}$} \\
\hline Uncertainty subscale & $18.2(29.3)$ & $21.4(31.3)$ & .13 \\
\hline Informed subscale & $37.1(38.5)$ & $36.6(37.1)$ & .86 \\
\hline Value clarity subscale & $30.7(36.6)$ & $36.2(37.1)$ & .03 \\
\hline Support subscale & $18.6(28.5)$ & $21.2(28.7)$ & .19 \\
\hline Overall score & $26.2(29.0)$ & $28.6(28.8)$ & .25 \\
\hline
\end{tabular}

*Percentages compare the percent up to date versus the percent not up to date for each row.

${ }^{\dagger}$ Satisfaction with clinician communication scores range from 0 to 4 . Response options included never, sometimes, usually, and always, which are scored as $1,2,3$, and 4 , respectively. ${ }^{9}$

${ }^{\ddagger}$ Decisional conflict score ranges from 0 to 100 , with 0 being no decisional conflict and 100 being extreme decisional conflict. ${ }^{10}$ An overall score under 25 is correlated with a greater likelihood of patients being able to make a decision, and score over 37 is correlated with a greater likelihood that a patient will not be able to make a decision.

Bolded $p$ values are statistically significant.

screening at the time of their visit and $31(3 \%)$ became up to date within 3 months (overall up to date rate of $64 \%$ ). Table 1 shows patient characteristics for patients who were and were not up to date. Age (odds ratio [OR], 1.03; 95\% confidence interval [CI], 1.01-1.05) and length of the patientclinician relationship $(<6$ months vs $5+$ years: OR, $0.49 ; 95 \%$ CI, $0.30-0.80$; 6 to 12 months vs $5+$ years: OR, $0.60 ; 95 \%$ CI, $0.36-0.99 ; 1$ to 3 years vs $5+$ years: OR, 0.67 ; 95\% CI, 0.48-0.95) were associated with being up to date, and there was no evidence of associations between being up to date and other clinician and patient factors.

Table 2 shows the patient report of colorectal cancer screening discussions. Only $36 \%$ of patients reported being given a choice about the type of screening test. Patients generally preferred to make their screening decision independently $(51 \%)$ or share the decision with their clinician (40\%). A total of $71 \%$ of patients reported that the locus of control 
for their decision was consistent with how they wanted to make decisions. Although patients reported high satisfaction with clinician communication, 33\% reported high decisional conflict (ie, score above 37), with greater uncertainty for the "informed" and "value clarity" subscales.

Patients who shared the decision with their clinician about screening options were more likely to be screened than those who reported independently making the decision (OR, 1.75; 95\% CI, 1.272.41). Even those who let their clinician make the decision for them were more up to date than those who made the decision themselves (OR, 1.94; 95\% CI, 1.20-3.13).

\section{Discussion}

In this sample of practices that care for more underserved patients, the longer the patient-clinician relationship, the more likely a patient was to be screened for colorectal cancer. Sharing the decision about how to be screened or even letting the clinician make the decision further increased a patient's chance of being screened, suggesting that the trust established through these relationships may be a key driver in patients overcoming barriers to get recommended screening. Patient trust in their clinician and clinician knowledge of the patient have long been shown to improve not only patient satisfaction but also adherence with care. ${ }^{11}$ These findings are further consistent with multiple studies that have linked the continuity of both primary care and specialty care relationships with reduced disease-specific and all-cause mortality. ${ }^{12}$ Others have shown that the receipt of primary care specifically is associated with improved quality of care, better health care experiences, lower costs, and even increased life expectancy. ${ }^{13-15}$ The clinician-patient relationship may be a key factor that leads to these benefits.

In this population, more traditional patient-level barriers to screening (race, employment, insurance, and education) and practice or clinician factors were not associated with being up to date. ${ }^{16}$ Clearly, on a national level, they remain significant barriers to colorectal cancer screening. However, in this sample of PBRN practices that are participating in research, are likely working on systems to improve evidence-based care, and where patients have a primary care clinician and have had an office visit, these barriers may be less significant. This idea is supported by the finding that the colorectal cancer screening rate was higher than national averages. Furthermore, now that first dollar coverage for colorectal cancer cost is mandated by the Affordable Care Act, cost may be less of a barrier; also, with multiple screening options, logistics may be less of a barrier. Another study in safety net practices found the top barrier for not receiving any screening was patients not knowing they were due for screening or their clinician not recommending screening. ${ }^{17}$ The longer clinician-patient relationships and greater clinician involvement in decisions observed in this study may be addressing these barriers.

A key strength of this study is that it uniquely linked the patient-reported process for care delivery (eg, decision-making) to the outcome of being up to date on colorectal cancer screening. Most prior studies have focused solely on patient-reported barriers to screening. In addition, this study examines multiple levels of influence on screening - the clinician, patient, and decision-making. A limitation is that we lacked power to compare subgroups of patients or factors influencing the receipt diagnostic follow-up. Of interest would be to compare those who were not up to date before the visit and became up to date with those who remained not up to date. Future work is needed to compare these groups of patients.

Overall, having a long-term relationship with a primary care clinician seems important to help ensure that more underserved patients get evidence-based preventive care. Promoting longitudinal patient-clinician relationships may be 1 strategy for reducing health inequities.

To see this article online, please go to: http://jabfm.org/content/ 33/5/779.full.

\section{References}

1. Bibbins-Domingo K, Grossman DC, Curry SJ, et al. Screening for colorectal cancer: US Preventive Services Task Force recommendation statement. JAMA 2016;315:2564-75.

2. Gupta S, Sussman DA, Doubeni CA, et al. Challenges and possible solutions to colorectal cancer screening for the underserved. J Natl Cancer Inst 2014;106:dju032.

3. Doubeni CA, Rustgi A. Racial disparities in colorectal cancer survival: is elimination of variation in care the cure? J Natl Cancer Inst 2015;107:djv229.

4. Laiyemo AO, Doubeni C, Pinsky PF, et al. Race and colorectal cancer disparities: health-care 
utilization vs different cancer susceptibilities. J Natl Cancer Inst 2010;102:538-46.

5. Jones RM, Woolf SH, Cunningham TD, et al. The relative importance of patient-reported barriers to colorectal cancer screening. Am J Prev Med 2010;38:499-507.

6. Sabatino SA, Lawrence B, Elder R, et al. Effectiveness of interventions to increase screening for breast, cervical, and colorectal cancers: nine updated systematic reviews for the guide to community preventive services. Am J Prev Med 2012;43:97-118.

7. Krist AH, Aycock RA, Etz RS, et al. MyPreventiveCare: implementation and dissemination of an interactive preventive health record in three practice-based research networks serving disadvantaged patients-a randomized cluster trial. Implementation Sci 2014;9:181.

8. Degner LF, Sloan JA, Venkatesh P. The control preferences scale. Can J Nurs Res 1997;29:21-43.

9. Agency for Healthcare Research and Quality. CAHPS clinician \& group surveys. Available from: https://www.ahrq.gov/cahps/surveys-guidance/cg/ index.html. Accessed November 2014.

10. O'Connor A. Decisional Conflict Scale. 4th ed. Ottawa: University of Ottawa; 1999.

11. Safran DG, Taira DA, Rogers WH, Kosinski M, Ware JE, Tarlov AR. Linking primary care performance to outcomes of care. J Fam Pract 1998;47:213-20.

12. Pereira Gray DJ, Sidaway-Lee K, White E, Thorne A, Evans PH. Continuity of care with doctors-a matter of life and death? A systematic review of continuity of care and mortality. BMJ Oopen 2018;8:e021161.

13. Levine DM, Landon BE, Linder JA. Quality and experience of outpatient care in the United States for adults with or without primary care. JAMA Intern Med 2019;179:363.

14. Basu S, Berkowitz SA, Phillips RL, Bitton A, Landon BE, Phillips RS. Association of Primary Care Physician Supply With Population Mortality in the United States, 2005-2015. JAMA Intern Med 2019;179:506.

15. Phillips RL, Dodoo MS, Green LA, et al. Usual source of care: an important source of variation in health care spending. Health Aff (Millwood) 2009;28:567-77.

16. Jones RM, Devers KJ, Kuzel AJ, Woolf SH. Patient-reported barriers to colorectal cancer screening: a mixed-methods analysis. Am J Prev Med 2010;38:508-16.

17. Muthukrishnan M, Arnold LD, James AS. Patients' self-reported barriers to colon cancer screening in federally qualified health center settings. Prev Med Rep 2019;15:100896. 